\title{
HISTORIA, CRÍTICA Y TEORÍA SOBRE LA POESÍA SEXUAL ÁUREA: comentarios a Fiebre de luz, de J. I. Díez
}

\author{
GASPAR GARROTE BERNAL \\ Universidad de Málaga
}

Recepción: 13 de julio de 2020 Aceptación: 20 de septiembre de 2020

Resumen: Comentario del libro de J. Ignacio Díez, «Fiebre de luz y río de corceles». Poesía y erotismo áureo (2019), dedicado a estudiar el tratamiento dado a la materia sexual por el Cancionero de obras provocantes a risa y por los poetas Garcilaso, Diego Hurtado de Mendoza, Baltasar del Alcázar y fray Melchor de la Serna, y asimismo a analizar el motivo áureo de la lengua y los cancioneros que en el siglo xIx publicó Peratoner. La obra se revela como una contribución decisiva para la historia de la poesía sexual del Siglo de Oro.

Palabras clave: poesía sexual, poesía del Siglo de Oro, Garcilaso, Diego Hurtado de Mendoza, Baltasar del Alcázar, fray Melchor de la Serna, Amancio Peratoner.

Abstract: Review of the book by J. Ignacio Díez, «Fiebre de luz y río de corceles». Poesía y erotismo áureo (2019), dedicated to the study of the treatment given to sexual matter by Cancionero de obras provocantes a risa and by the poets Garcilaso, Diego Hurtado de Mendoza, Baltasar del Alcázar and Melchor de la Serna, as well as the analysis of the golden motif of the tongue and the cancioneros published by Peratoner in 19th century. This work is revealed as a decisive contribution to the history of sexual poetry of the Spanish Golden Age.

Keywords: Sexual Poetry, Golden Age Poetry, Garcilaso, Diego Hurtado de Mendoza, Baltasar del Alcázar, fray Melchor de la Serna, Amancio Peratoner.

AnMal, XLI, 2020, pp. 271-291. 
Uno de los mejores y más constantes estudiosos de la poesía sexual del Siglo de Oro, J. Ignacio Díez, dedica su nuevo libro a otro de los maestros de la filología puesta al servicio de ese empeño, José Lara Garrido, de cuyo poemario de 2018, Cancionero del amor fruitivo, toma el endecasílabo para su título (Díez, 2019: 14). En 1995, los tres volúmenes de la colección Erótica Hispánica, dirigida por el profesor Lara, «comenzaban un dibujo textual en una época dominada por la gaseosa teórica y ofrecían un testimonio contundente sobre la riqueza e intensidad de la erótica hispánica», según indica Díez (101) ${ }^{1}$. Un cuarto de siglo después, «Fiebre de luz y río de corceles». Poesía y erotismo áureo conjunta siete de los estupendos artículos con que, entre 2006 y 2019, Díez ha seguido contribuyendo a paliar el «minucioso descuido» (11) del examen de la literatura sexual española. Esos trabajos conforman ahora seis capítulos que analizan el Cancionero de obras provocantes a risa, textos de Garcilaso, Hurtado, Alcázar y Serna, y el motivo áureo de la lengua, así como un apéndice sobre los cancioneros que en el siglo xix publicó Peratoner.

«Tampoco es ya un secreto que los poetas de los Siglos de Oro dedicaron una buena parte de sus esfuerzos a componer textos eróticos» (222). En el inicio de ese itinerario, el Cancionero de obras provocantes a risa. Si la «estrategia comercial» de Hernando del Castillo en su Cancionero general de 1511 «se apoya en la obvia verdad de marketing de especializar la oferta para grupos distintos de consumidores», este de 1519 atendería «una demanda» que también pudo haber fabricado (19-21). Sugerente hipótesis de Díez que, conectable quizá con otra práctica editorial, la «avalancha» entre 1885 y 1887 de «bibliotecas verdes» $\mathrm{y}$ «picantes» «más o menos pornográficas y traducidas» (224), constituye una de esas constantes que superan la actual organización de la historia literaria (41). Castillo recorrió en 1511, «alfa y omega» (17), un trayecto inaugurado con Obras de devoción y moralidad y clausurado con Obras de burlas. Modificando la reedición de esta última sección en el Cancionero general de 1514, el de obras provocantes a risa constituyó, según Cerezo, un exento impreso de textos obscenos, pionero en Europa (22). El efímero paréntesis de poesía sexual impresa que entre 1511 y 1535 dibujaron estos cancioneros fue cancelado con los cambios operados sobre la edición de 1535 del General, de la que los propios censores dijeron haber hecho desaparecer «algunas obras que eran muy deshonestas y torpes», a lo que se añadiría «la probable destrucción de los ejemplares» del Cancionero de obras provocantes a risa (19). Que presenta «abruptamente» los poemas: $\sin$ «introducciones», «ni intenciones, ni partes, ni comentarios», su «relación directa texto-lector» puede ser «producto de las prisas» —ese factor esencial en la industria editorial, al que entiendo que pudieran sumarse preocupaciones ligadas con el

\footnotetext{
${ }^{1}$ A partir de ahora citaré entre paréntesis la(s) página(s) del libro que comento, sin más indicaciones.
} 
ahorro- - pero «se aviene muy bien con la poética de lo explícito» que evidencian Pleito del manto y Carajicomedia, parodias «inequívoca y abiertamente obscenas», entre las que el Cancionero sitúa «cincuenta y seis composiciones, muy variadas» y en diversa medida «afectadas por esa potencia sexual (u obscena, si se prefiere)» (36-37).

Con todo, el Cancionero de obras provocantes a risa presenta «la unión de un lenguaje obsceno, por explícito, y una expresión erótica que maneja lecturas que hay que decodificar» (45) por construirse en virtud de un recurrente código cerrado que apenas sería usado por Garcilaso. «Estudiar el erotismo» en su obra «obligaría probablemente a centrarse», pues, «más allá de los límites expresivos de la tensión erótica subyacente en el petrarquismo, en los poemas cifrados o en código» (58-60). Ampliando las páginas que en un libro imprescindible dedicó a Garcilaso (Díez Fernández, 2003: 84-92), el crítico analiza ahora sus sonetos XXIII, XIII, XXII y VIII (60-64). Tras leer este último junto con los testigos de época — concepto que definí en 2010 y aplica Díez (83-84) - Castiglione, Ficino y Herrera, la interpretación erótica sostenida por Llosa en 2009 no queda validada (65-74). Es que, evitando «las descripciones» y «la exposición sexual», Garcilaso prefirió la «opción estilística» de «la "obscuridad honesta" propia de los epitalamios», «que con mucha frecuencia se oscurece aún más al componerse en latín» (74-75), lo que entiendo como indicio de selección de un receptor bilingüe. Minuciosamente revisa entonces Díez otros pasajes de Garcilaso: «el pudibundo» (61) Herrera hubo de montar, sobre égl. II, 1401-1418, una teoría neoplatónica de la honestidad léxica (fonética y semántica); en torno a los cabellos de égl. III, 93-100 y 281-283 y canc. IV, 101-107, el comentarista resaltó el indigno verbo escurriendo, mientras que en la canción $\mathrm{v}$ anotó como lujuriosa su concha de Venus —en esa estrofa funciona también la conmutación sexual de al remo condenado (Garrote, 2020: 78)_; por fin, para los sonetos XI y IV, parte Díez de dos lecturas dilógicas: las de Navarrete en 1997 y Garrote en 2011, respectivamente. Pero la poesía de Garcilaso, atenta más a Virgilio que a Ariosto, no dio pie a imitaciones eróticas, quizá porque no se percibiera como tal, si bien Díez recoge mi comentario sobre su influencia en un soneto sexual del Antequerano (80-86). Añadiré que el xx de Garcilaso se cierra con un atajaré la guerra del camino en que de pasada se fijó Herrera, quien en 1580 anotó ahí como «Alegoría i traslación del tocamiento» los sintagmas duros vientos y en tiernos pensamientos, mientras que en la canción Iv, 44 percibió «La sensualidad» tratada en sus para él justos términos, según apuntaba con agrado: «describe hermosamente aquella interna discordia i guerra en que contrasta reluchando la razón con el apetito sensual i bruto» (Herrera, 2001: 410 y 517).

Frente a Garcilaso, Hurtado de Mendoza sí empleó el código abierto o bruto. De las 18 composiciones que forman el «núcleo muy duro» (108) de su 
poesía, el editor de Obras del insigne caballero don Diego de Mendoza, fray Juan Díaz Hidalgo, mencionó tres: «azanahoria, cana, pulga» (120), «alusión» que «demuestra holgadamente que al menos en 1610 se puede leer pero no publicar» poemas como los que representa A la zanahoria, «sucísimo» según el anotador del manuscrito BP 2805 (123). La edición de 1610, que se vendió mal, iba dedicada al VII conde de Tendilla, quien «trataría de usarla para asentar su prestigio con un antepasado tan culto como guerrero», lo que excluiría de esa imagen al Hurtado burlesco (91 y 93-94). Con todo, la edición pudo «permitirse aceptar» algún texto «limpiamente erótico», como «Venus se vistió una vez...» y la segunda epístola a María de Peña, que contiene «pasajes, de una suerte de historia sexual» que el glosador de BP 2805 censura (97-98).

Con una de las finísimas observaciones que tanto destacan en su labor crítica, Díez asienta que Baltasar del Alcázar compuso su poesía en «una sociedad muy religiosa y más libre al mismo tiempo por mantener muy ritualizada la religión» (148). Caracterizan a los menos de 70 epigramas de autoría segura de Alcázar la «reacción burlona a las seriedades del maestro Herrera y sus más fieles imitadores» y el recurso a «un ingenio que puede aludir a lo innombrable» (137-138). Es que Alcázar mantuvo la arraigada práctica de codificación sexual dual, abierta y cerrada, unas veces en epigramas «provocadoramente eróticos»y otras dispersando «ciertas pistas»; creo que las del 149 (templo, velo, gloria), más que «religiosas» (148) serían mitológicas, según revela la mención final de Acteón. Las «situaciones insólitas» de esta poesía, «apoyadas lejanamente en los epigramas de Marcial o en resumen de facecias de tradición oral», agrandan «la brecha» con el petrarquismo — quizá mejor que «con la poesía italianizante», más plural-, dentro de «un no explícito pero deducible contexto prostibulario» «o tabernario» (139). Pero «quizá» la «columna vertebral» de los epigramas de Alcázar sea el «abundante uso de los dobles sentidos», sobre todo sexuales, «frente a declaraciones muy crudas en Marcial» (142-143). Si el anfibológico ojo del 142 de Alcázar apunta «sin duda al juego de palabras» marcialesco «entre culus y oculus» (I, 92), en la versión muy libre de Marcial, Iv, 65 que es el 157, con solo el un ojo «puede remitir burlonamente a la pureza de Catalina de Alejandría» (145-146). Creo que no cabe olvidar que Catalina era nombre asociado a lo escatológico y lo sexual, según detectó Sepúlveda (2001: 293-295), quien mencionaba entre otras conexiones a Catalina de Alejandría y este epigrama de Alcázar; de hecho, el 158 insiste en el «paso» Catalana-Catalina, al tiempo que presenta una «cierta oscuridad referida al número tres», igual que en el 129, referido a una mujer virtuosa (149), otro signo de código cerrado que parte de virtud, 'pene'.

No menos burlesco que Alcázar se presenta fray Melchor de la Serna en los «tres temas o géneros» del elogio, las preguntas, y las recetas y remedios, cuyo «placer transgresor» es, «más que una contestación a un sistema de valores», 
«una broma entre amigos» (164-165). Con el «milagro burlesco» del Sueño de la viuda, 155-216 y su loor del falo, Serna incorpora el «elogio erótico» que, relacionado «con la técnica del enigma», ya practicó Hurtado en A la zanahoria, A la cola y Fábula del cangrejo (164-166).

Frente a la raíz clásica del elogio paradójico, el género de las preguntas es una pervivencia cancioneril que Sebastián de Horozco sostuvo en el siglo XVI como «demostración del dominio técnico», como cuando «a veces maneja dos respuestas para una misma cuestión», una de predominio de «elementos denotativos y burlescos» y otra de «toques serios o científicos». Entre los textos áureos de preguntas antologados por Labrador y DiFranco en $2003^{2}$ «no se incluye ninguno erótico» - aunque en código cerrado me parece que pudiera funcionar al menos el primero, nucleado en torno al dilógico penar-, si bien contienen «gérmenes» de «desarrollos paródicos» como «el barniz científico o erudito, el didactismo, etc.», tratando de medicina, la enfermedad y el amor, y manteniendo «el imprescindible ingenio» o «la importancia del juego». También el «propicio» soneto dio cabida al género: «¿Cuál será la causa, mi Damón...» de Aldana; Soneto pícaro a la pregunta de una monja de Barrionuevo; Respuesta a una dama qué era lo mejor que hallaba en su cuerpo, atribuido a Iriarte (167-172). Fray Melchor incluye el tópico del melindre femenino, la indicación no eufemística y el acogerse a la autoridad de Ovidio en su Pregunta a un amigo. En las demás se «distancia de las convenciones del género cancioneril»: su soneto sobre la llave y el candado conecta con «los anillos milagrosos de Mendoza» en El cuerno y «las cerraduras y llaves de Felipe, el celoso extremeño cervantino»; Respuesta falsa, sobre monjas, un tema predilecto entre frailes autores de poesía sexual, trata, como Horozco, n. $^{\circ}$ 57 , del «envío de un instrumento que hay que templar», donde clavicordio quizá esconde «connotaciones eróticas» —-según ya ocurría con los estrumentos musicales de Juan Ruiz (Miaja de la Peña, 2012)—; Respuesta de una dama que pedía el virgo a su galán «juega insistentemente» con flor y su técnica se asemeja a la de El tomar de las mujeres de Salinas (n. ${ }^{\circ} 279$ ), donde «los diferentes complementos (tomar acero, tomar dinero, etc.)» logran «un equívoco muy rentable eróticamente»; por lo demás, flor, 'falo', muestra «su conexión con la virginidad», y una de las quintillas finales emplea los dilógicos camino real y lanza de paja (172-178).

En cuanto al género de recetas y remedios, figuraba en A la zanahoria de Hurtado, en la Receta de Horozco (n. ${ }^{\circ}$ 58) a una dama que deseaba empreñarse, con voces como dura, movimiento, obra, natura y cabalgadura, y en $A$ dos recetas que trocó un boticario, de Salinas. Frente a los dos primeros, Serna

\footnotetext{
${ }^{2}$ Es costumbre del libro de arena de la Red cambiar sus enlaces: esa antología ya no se localiza en el registrado por Díez, sino en http://juanalfonsodebaena.org/Novedades/Revista/ArticleID $/ 118 /$ Genero
} 
«parece decantarse por lo que de ridículo tiene el género de las recetas burlescas» en Remedio para la madre, que une «posibles dilogías eróticas» (sangrar, rabillo, untar) y una «ridiculización de lo tradicional» de los métodos contra el mal de madre, y en Receta que dio a una dama para el dolor de muelas, en que «resulta malicioso el interés por explicar la conservación cuidada de las recetas» y se mencionan «las glosas de Belerma» (178-182).

Díez dedica su capítulo final al «sentido más físico y sexual» de la lengua, cuyos «problemas se intuyen en Covarrubias», que definió en latín: pars corporis nobilissima voci formandae, dignoscendique saporibus destinata, ita dicta quod eius ministerio lingentes utamur (190); es decir: «nobilísima parte del cuerpo destinada a formar la voz y apreciar los sabores, así llamada por su función de lamer». Muy «presente» en la poesía áurea, la lengua fue usada «casi siempre» «en una misma dirección, nada erótica», de modo que cuando es «objeto sexual tabú» se oculta de forma «automatizada» con «menciones metonímicas o metafóricas» y «raras veces se nombra en las descripciones» (187). Es que el «beso con lengua» implica «una actividad sexual» (198). Por eso los poetas suelen «detenerse en el lugar privilegiado de la boca y, de manera especial, en los labios, signos tolerables para el decoro social y literario», pues «la lengua parece constituir una presencia generalmente lasciva», de modo que «la tendencia a sugerir "lo vedado"» (Hurtado) o «"lo mejor"» (Aldana) «no suele alcanzar la lengua», frente a por ejemplo las tetas que figuran en la descriptio puellae, «porque la lengua es un objeto erótico de mayor alcance en su constitución del tabú», así que un «cierto paralelismo entre lengua y falo» permite «que los dos apéndices compartan algunas imágenes: la serpiente o la sin hueso» (192-193). Los «poemas que utilizan la lengua con su contenido más físico», en que «se exalta el placer», presentan «un encuentro sexual» $\mathrm{y}$ «menciones y descripciones muy explícitas», y forman una «doble adscripción»: «textos eróticos (y generalmente burlescos)» que describen «los actos sexuales o las partes de la amada y del amado», como el soneto «Cierta señora se soñó durmiendo...» del ms. RAH 9/5870, que relata «un encuentro sexual pleno, por más que soñado», «utiliza la lengua» «con un sentido sexual» (diole lengua) y conecta literalmente con otro de PESO sin lengua; y los «textos epitalámicos» que «celebran esos mismos actos sexuales»: en 2006, Ponce Cárdenas rastreó «cierta poesía sexual en la tradición clásica y neolatina, la de los epitalamios, poesía seria y honorable», que «en la descripción del ample$x u s »$ o abrazo incluye «referencias» a los besos, la boca, la lengua, el entremezclar saliva, chupar y lamer, igual que los Basia de Juan Segundo (15111536), donde «aparece la lengua» y algún poema opera con el doble sentido de anima, 'aliento' y 'alma' (190-196).

En los siglos XVI y XVII «Italia castigaba con mayor severidad el beso que el rapto», dado que «el beso en público se tomaba mucho más en serio, como 
prenda de unión, en Italia que en el resto de Europa», e incluso en Nápoles «se condenaba a muerte a quienes besasen en público a mujer casada» (Solé, 1976: 115-116). Se comprende así la neoplatonización del beso ejecutada por los autores italianos con que Díez se encuentra en sus pesquisas. Según Castiglione, es el beso «más aína [...] ayuntamiento de alma que de cuerpo», lo que «convierte a la boca en la puerta de amor», «una puerta honesta»; la doble formulación «más célebre» de esa idea se halla en Boiardo, Innamorato, I, XIX, 61 y Ariosto, Furioso, vII, 29, 7-8, quien asienta que «con la lengua la unión de las almas es más perfecta, más estrecha», aunque el testigo Trillo juzgara la imagen «indecente, indecorosa, lasciva, ajena de la alteza y gravedad de un poema heroico». Esta línea boiardesco-ariostesca trazada por Ponce Cárdenas fue seguida en la poesía española por «Aviendo sido ya más combativa» $\mathrm{y}$ «O dulce gusto estraño y peregrino», dos sonetos de Silvestre «que asocian, de manera menos escandalosa que Ariosto, el beso y la fusión de las almas» y evitan «la menor alusión a la lengua»; por Medoro y Angélica de Aldana, en un fragmento de «pulsión sexual» que juega «con los significados de "paz"» - y donde añadiré que el verso «paz de su luz tomó dentro en la boca» conmuta paz y tomar, lo que implica que el beso es un tipo de «ayuntamiento carnal» deseado por los «enamorados castos» (Castiglione) —, aunque Aldana elude la lengua incluso en sus sonetos «de intensa carnalidad», si bien en «y allá en el alma dio del caso aviso» creo que opera el signo de código cerrado alma, 'pene'; por Barahona y la «doblada lengua» de la «escena fuertemente sensual» de Las lágrimas de Angélica, II, 30; por el madrigal Pinta ejecuciones de amantes, atribuido a Quevedo, en que las lenguas trocaban y cuyo amplexus, «en clave pastoril o rústica», «tiene la particularidad de detenerse en un orgasmo simultáneo» expresado con vueltos los ojos; y por la Descripción del coito de Gabriel de Henao, tres octavas sobre otro amplexus pastoril cuya «elaboración del tópico ariostesco» «podría demostrar el valor sexual de la expresión»(197-204).

Forman otra línea los poemas con lengua «en un contexto abiertamente sexual»: el de Álvarez de Soria y su amplexus ante la mirada de Venus incluye un explícito culeando; uno de los sonetos de Lope sobre los mansos, con un personaje cuyo nombre coincide con el de otro del Furioso, «Vireno, aquel mi manso regalado...», fue excluido de la imprenta porque «insiste en un tabú, de manera muy calculada». Por el contrario, hay sonetos «sumamente eróticos» que «evitan la menor alusión a la lengua», como «Bésame, espejo dulce, ánima mía» (PESO); otros, con lengua y besos, añaden «un sentido trágico» («Boca con boca, aliento con aliento...», atribuido a Henao y a Villamediana) o «elementos violentos», como «Con la lengua los labios apercibe...», de Lupercio de Argensola (204-206). Sobre este último añadiré que el motivo de «Francia, do el besarse es ley forzosa» fue continuado por el Iriarte de Poesías lúbricas: «Franceses, habláis de un modo / y de otro soléis obrar: / no es nada 
en Francia el besar, / y besar lo dice todo» (ms. BNE 3744, fol. 14r). Costumbre que no solo dejaba perplejos a los españoles: «los viajeros italianos continuarán mostrando su extrañeza y su encanto ante las prisas que se dan las francesas en besarles» (Solé, 1976: 116).

Con o sin lengua, cuatro sonetos de Góngora (198 y 206-210) se vinculan con el beso: «De pura honestidad templo sagrado...» y su «pequeña puerta de coral preciado», $\tan$ «honesta»; «La dulce boca que a gustar convida....»; «Ya besando unas manos cristalinas...», «indecente» para el padre Pineda, a pesar de que «una boca con dos labios» excluye la lengua, «quizá para evitar un grado mayor de erotismo», y «Al tronco Filis de un laurel sagrado...», con libar, «la imagen de los dos labios» y el lamer sorteado por Covarrubias. En «otro registro», «Yace aquí Flor, un perrillo...» presenta los dobles sentidos de culantrillo, flor y lengua. Experto conocedor de la poesía áurea, Díez multiplica los casos (209-211): Responde el auctor por el doctor Pero Vázquez [...], de Horozco, «se carga de espesos contenidos para manejar un uso tabú y un doble sentido» en cabo, caño - y añadiré que en la traducción (rabo) que sigue al eufemismo salvohonor - y lengua, 'palabras' y 'lengua que hurga en el culo'; en Jacarandina de Quevedo, sacar la lengua sea quizá «un reclamo sexual», a no ser que lengua, 'pene', según la hipótesis de Díez; la veta «popularizante» de «Atyna que dais en la manta...» se nuclea en torno a la oposición «la lengua en su sentido traslaticio» / espada del impotente, con una posibilidad de cunnilingus, y en dos seguidillas contiguas de PESO, mientras que la segunda transita la línea Boiardo-Ariosto, la primera «juega con la malicia de modo blasfemo»: «Dame lengua, mi vida, pues das lo demás, / que no es misa de réquiem que quita la paz».

Fueron «diversos editores» decimonónicos los que insistieron en que había «una tradición erótica, también en la literatura española» (228-229). Por eso Díez plantea la necesidad de «estudiar la erótica en sus diferentes manifestaciones, como esos cancioneros eróticos que, publicados a finales del siglo XIX, aprovechan un cierto aire de libertad» y permiten «el desembarco de la poesía erótica de los Siglos de Oro en la visibilidad de la imprenta». Amancio Peratoner, «uno de los erotógrafos más activos» del XIX, preparó entre 1874 y 1882 «obras de divulgación (o de supuesta divulgación)»: «traducciones» «aumentadas o refundidas» que «se continúan con un estudio que se presenta como muy sesudo pero que atañen a cuestiones» «buscadamente muy provocadoras», con predominio de «la temática sexual», «tanto por la demanda del mercado, como por una ideología concreta, que Pura Fernández conectó con un grupo heterodoxo de editores» que integraron «el combate en el terreno de las ideas» y el «negocio editorial» (215-218). Movieron a Peratoner el «interés mercantil» y «la demanda del público», «imposible de cuantificar» (226-228), aunque entiendo que indicios sean el número de reediciones y las tiradas. Estas 
oscilaban, por lo general, entre 1.000 y 2.000 ejemplares en la imprenta madrileña de 1896-1913 (Botrel, 2018); de modo que las 8 ediciones y reediciones de los cancioneros de Peratoner que menciona Díez, con facilidad pudieron haber llegado a varios miles de compradores en el lapso 1864-1881.

Esos cancioneros fueron cinco: Museo epigramático o colección de los más festivos epigramas (1864; $3^{\mathrm{a}}$ ed. 1866, con un añadido de más de 200 páginas que daba un total superior a las 580); Venus retozona (1872, 198 pp.; $2^{\mathrm{a}}$ ed. 1892, 205 pp.); Flores varias del Parnaso (1876); Juguetes y travesuras de ingenio de D. Francisco de Quevedo Villegas (1876, 206 pp.), y Venus picaresca. Nuevo ramillete de poesías festivas dedicadas a la juguetona musa de nuestros vates (1881, 207 pp.). Esta «red» «puede crecer en frentes diversos y aprovechar materiales previos»y «no pierde de vista los aciertos de competidores, como los del también prolífico Lustonó» (234-235). «La mezcla» es su «tónica»: prosa y verso, textos del pasado (excepto los «medievales») y del presente («mucho más abundantes»), erotismo y otros contenidos en que prevalece «un sentimiento lúdico» (228-230). «Hay una cierta magia (u otra razón práctica, que a mí se me oculta, al confeccionar un libro) en la predilección por cifras muy próximas en la paginación», entre 205 y 208; pero más bien rige la razón práctica que «persigue un formato de bolsillo» «orientado a unos tipos de lectura determinados» y, «para abaratar costes» y «evitar problemas con la censura», no incorpora ilustraciones (232); por lo demás, como un pliego contenía, en $4^{\circ}, 8^{\circ}$ o $16^{\circ}, 16$ páginas impresas (Botrel, 2018: 218), las habituales 205-208 se sitúan en el radio de los 13 pliegos, mientras que a 37,5 llegaría el Museo. La recepción de la poesía sexual áurea en el XIX hubo de lidiar con que «muchas» de las atribuciones de Lustonó y Peratoner, quien lo seguiría, «son erróneas o carecen de base» (233), y se focalizó en Quevedo, «ingrediente esencial de los cinco cancioneros» de Peratoner, así como en «Alcázar, Lope, Góngora» (235).

Atento a los hechos, es decir, a los textos, Díez afirma que «los mecanismos expresivos del erotismo (o de la obscenidad) quizá no obedecen exactamente a las mismas reglas que organizan la historia de la literatura» (41). Así, las herramientas del bufón (agresividad, parodia, humor y obscenidad), recordadas por Santiago Ruiz con Cicerón (45), atraviesan los periodos de tal historia, como también el procedimiento de «asimilar la obscenidad a las burlas», que según Salido López «son, en su raíz, un ejercicio de ingenio» (33).

Como historiador literario, Díez identifica un claro hilo conductor que va conectando y ordenando de modo pertinente los textos, según muestran los excelentes capítulos $\mathrm{v}$, sobre los géneros del elogio, las preguntas, y las recetas y remedios, y vi de Fiebre de luz. Libro que atiende de este modo jalones esenciales para una historia de la poesía sexual áurea, en el siglo que va del 
Cancionero de 1519 a Góngora. Las páginas de Díez ofrecen por lo demás esbozos de otros géneros y subgéneros de la literatura sexual: el goliárdico de la disputa (41); el epitalamio, dependiente del «delineado sutil de un erotismo oscuro y honesto» «que se inserta en la poética "seria" o culta o simplemente publicable» (59 y 75); el inventario prostibulario, ampliamente extendido por todas las literaturas (49), y lo didáctico, esa coartada: «¿a quién engaña la parodia del didactismo dentro de la erótica?» (184). También, el epigrama, «pieza de gran rendimiento para la expresión del erotismo»: «Memorizables, sus frecuentes ocho versos» en Alcázar «permiten un juego social» a través del recitado «en la poblada, rica y cosmopolita Sevilla del siglo XVI» y la conexión, subrayada desde el Libro de retratos de Pacheco, con Marcial, a quien Alcázar no traduce, sino que «adopta» su «técnica»: «la división de las dos partes de cada epigrama con su anécdota y su agudeza» (137-138), según una «concepción ingeniosa» «que comparte con el chiste» $\mathrm{y}$ «reserva su premio para quien desvele todas las claves hasta alcanzar la maliciosa o no permitida en términos legales» (146). Díez recurre a un «triplete explicativo» del epigrama: «el humor personal y el cultivo de la amistad y el sentido de la pertenencia a un grupo (con prestigio humanista), más el juego con el sistema de géneros o meramente literario (con sus hegemonías y sus rebeldías o contrastes... que también incluye el humor)» y «una burla (mejor que crítica) social o legal de costumbres» (140-141). Asimismo, Díez va hallando motivos anatómicos (boca, labios, lengua, mano, pene) y posturas o acciones (beso, amplexus, coito) que, con vocabulario no dilógico, caracterizan a la dinámica poesía sexual frente a la quietud de la amorosa. O frente a la satírica: cuando funciona «no como metonimia de los rumores, la maledicencia, la tendencia a hablar demasiado», sino «como objeto sexual», escasas son las menciones que la poesía áurea registra de la lengua, «quizá porque se consideran lascivas o inapropiadas tanto en el sistema moral como en el literario» (212), aunque «el valor del motivo» en cada poema «no tiene por qué coincidir» (207).

El sexo es el más persistente o arraigado universalmente de los tabúes. Más quizá que el de la muerte, de la que sí trata largo, tendido y públicamente, entre otras, la literatura funeral, aunque sea para atenuarlo mediante consolaciones y metafísicos juegos de palabras. Atenuación y eufemismo, como tratamientos textuales del tabú, son objetos de estudio de la filología, a la que, por su propia especialización, escapan las razones antropológicas de que tanto gusta la especulación en la teoría. En especial cuando trata del silencio, espacio que por carecer de límites nítidos pudiera parecer vasto. El método de Díez, centrado en los textos, permite obtener brillantes resultados críticos, no menos que principios generales para compre(he)nder la diacronía que conforma el objeto de estudio seleccionado, la «poesía erótica o sexual» (59); 
disyuntiva que aclara esta identificación: «La poesía erótica es la poesía sexual» (56).

Casi superada la historiografía sesgada de los dos últimos siglos, «ya no caben dudas de que lo sexual es una parte temática más de la literatura» (133). Vence a los prejuicios contra esa zona el estudio: el trabajo. Por ejemplo, de exploración de las lindes — verbales: otro asunto, pues, filológico- en el par honestidad / obscenidad. Díez compara lo cambiante del concepto de obscenidad con el significado del desnudo, habitualmente erótico y conectable a su vez con las condiciones del consumo, restringido o permitido (77-79), y con el propio tabú, modificable según la situación, incluso dentro de una misma cultura como la latina (141). De modo que hay «la posibilidad de que en algunos momentos antes del siglo XIII lo obsceno no fuera tal sino» un uso normal en una lengua libre del tabú sexual (34), mientras que en los siglos XVI-XVII hubo «unos límites anchos y variables de lo erótico que no coinciden con las ideas preconcebidas que hoy se aplican sobre la producción de los Siglos de Oro» (152). El magnífico historiador de la literatura que es Díez busca la esquivada definición de obscenidad no en los axiomas teóricos previos, sino en indicios como el epigrama XII, 43 de Marcial o en el testigo de época Erasmo (142 y 30). Y sobre todo en textos primarios que analiza cuidadosamente. La lectura de los seis poemas suprimidos del Cancionero general en 1535 (Visión deleitable, uno de Diego de San Pedro y cuatro del Ropero), «puede funcionar» así como «termómetro de la obscenidad»—lo que en otro lugar he llamado grupo de control textual — para hallar «qué posibles criterios sigue el editor en los cambios» (36); idéntica función cumplen «las composiciones suprimidas en las dos primeras ediciones» —en 1514, las de 1511- del Cancionero general (38-39) o los textos que Hidalgo mencionó y excluyó en 1610 de las Obras del insigne caballero don Diego de Mendoza, con lo que «el editor reconoce que la fama de Mendoza no se ha basado en los horizontes que va a dibujar su libro», que busca «un cambio en los motivos de una justa fama poética» (89).

Este asedio permite comprender que del par deshonesto (u obsceno en cuanto ocultable) / honesto, deriva el doble sentido atribuido a la lengua, «el físico y el metonímico», entre los cuales no siempre es fácil distinguir, como en $A$ la zanahoria, 88-90, «donde podría contenerse una referencia maliciosamente doble», «una prueba más de la natural (iy bendita!) resistencia de la realidad literaria a las taxonomías» (187-188). También el «carácter erótico (o "vicioso") del beso depende» de «exquisitas circunstancias» detalladas por Castiglione, según el cual «unas mismas cosas» son «deshonestas» en el amor «vicioso» y «honestas» en el «virtuoso», como tomar la mano o besar (194), afectados por esa bipolaridad. Que rige asimismo a la obscenidad que en 1526 caracterizó Erasmo como el «nombrar directamente lo que la decencia trata de 
otra forma y describir actos indecentes aunque el lenguaje no lo sea» (30). Así que Díez distingue entre obscenidad de ideas, identificable con la denotación (102) y «meridiana» en el poema 53 del Cancionero de obras provocantes a risa, aunque recurra al eufemismo salvonor (47), y obscenidad de palabras, que en Pleito del manto y Carajicomedia, que reflejan la «abundancia» de coño y carajo (30-31 y 43), «descansa» en un vocabulario que en sus «bromas eróticas» adquiere un doble sentido: apetito, aliviar, enojo, derramadas, plazen (21). De hecho, aunque la «parodia de la técnica jurídica» que es el Pleito sea «una buena muestra del uso abundante de términos obscenos», son en ella «frecuentes los dobles sentidos» de miembro, potencia, fuerza, meter, recio, flaqueza, enconado, encerrado, derecho, profundo, justo, vía, puerta, sepoltura o sellar (41-43).

En cuanto basadas también en textos, cabe examinar filológicamente la percepción y la recepción históricas de la obscenidad. Díez constata que en los siglos XIX y xx el Cancionero de obras provocantes a risa se entendió «inequívocamente obsceno» (29), aunque, como no se dedica «monográficamente al sexo» (35), «lo obsceno no es lo dominante» en él (24). Dirigido a la «alta sociedad» del xv, en que convivieron «la poesía amorosa y la obscena» (28), este Cancionero incidió probablemente en «la interpretación humorística de la obscenidad» (24), dado que «la burla» «preside la selección de los textos», y junto con el antisemitismo, la misoginia y la crítica social, agrupa a la temática obscena, «que se basa en la ruptura del tabú, en la repetición de lo prohibido» $\mathrm{y}$ «la tradición ingeniosa» (35).

Las muy acertadas reflexiones de Díez son estímulo para las que desarrollo ahora. Siendo «el sexo» «un tema literario más» (50), parece lógico que el hiperónimo sexual rija, historiográficamente, una secular familia de etiquetas. Aquellas que, referidas a asuntos que van desde la genitalidad hasta la sensualidad, fueron marcadas peyorativamente en la historia y - lo que es peor-en la historiografía. Para ambas, hubo materias y expresiones que respondían a un modo deshonesto, vil, obsceno, torpe, bruto, bestial, lujurioso... Pero desde el siglo XIX hasta hoy domina el hiperónimo erótico, impuesto por una gazmoña academia y dotado de un carácter pretendidamente más neutro, que se viene abajo cuando colide con el también decimonónico marbete pornográfico. Esta inercia bisecular es tan fuerte que erótico y erotismo se siguen salvando como hiperónimos: «La obscenidad se aleja del erotismo» por «focalizarse» en «la transgresión de un tabú a través de la reiteración nominal», y «se acerca» a él «por su oposición a lo honesto» y por su connotación sexual (31). Afirmación que, nada disonante con el estado de la cuestión actual, incorpora a su transtemporalidad historiográfica marbetes históricos de tiempos distintos. En efecto, obscenidad designó la expresión abierta de lo sexual —como 
sutileza lo hizo para la forma atenuada—, pero solo hasta la modernidad, mientras que desde entonces erotismo y pornografía aluden a los respectivos modos light y hard de dicha expresión. Por lo demás, está la dialéctica erotismo / pornografia tan asumida que no se la percibe como lo que es: una hipótesis asentada desde solo hace algo más de un siglo y exclusivamente válida, en todo caso, para la literatura moderna y contemporánea. Y como muestra Díez, lo que la someta a prueba de resistencia no será la especulación sobre las etiquetas, sino el análisis de los textos. Que puede falsar tal hipótesis: el epigrama 157 de Alcázar, por caso, «destruye los improbables límites entre erotismo y pornografía» (146). Esa hipótesis está, por si fuera poco, sujeta a doble tacha: va marcada por una moralización que, avergonzándose de sí misma, necesita disfrazarse; y, sobre todo, practica la identificación entre el investigador y la reprobación sostenida por el (o dentro del) objeto que estudia, desde las Partidas alfonsíes hasta Baroja y Unamuno. Pero aunque la historia valore siempre, que lo hace, la historiografía jamás debiera permitirse tal exceso.

Díez aplica la distinción que, pretendiendo superar de forma neutra o historiográfica las denominaciones históricas valorativas, establecí entre «código literario sexual abierto y código literario sexual cerrado» (32), que se formalizaron «con sus técnicas e intereses, y también con "poemas mixtos"» (58). Diferenciación presente en otras literaturas: la poesía en francés de Marot (1496-1544) es de «ingenio eufemístico o metafórico», mientras que su obra neolatina es explícita y admitida en los ambientes cortesanos (36). Creo que esta dualidad de códigos sitúa el análisis en una perspectiva filológica, en la que el «vocabulario directo o prohibido» del abierto (deshonesto hasta el siglo XVIII; erótico, en cuanto monotemático, o pornográfico desde el XIX) contrasta con la «expresión en el código cerrado», al menos bitemática y basada «en un complejo, elegante y despistante juego de dilogías, insinuaciones, metáforas y ocultaciones no siempre recuperables con toda precisión» (155), pues «casi siempre debe usar mecanismos de ensombrecimiento cuando se trata de textos impresos» - aunque ya se practicaba antes de la imprenta-, «de modo que aparece sugerido o aludido o muy codificado», a través del «ingenio» (134). Añadiré que por eso desde Juan Ruiz hasta Gracián se llamó sutil al código cerrado, que «persigue obtener la admiración de una técnica y de una osadía temática» y «busca una comunicación ingeniosa con el lector» (184). En efecto, este «desarrollar un tema prohibido de manera ingeniosa» exige la complicidad con el receptor y es desafío para otros poetas (106) dispuestos a probar «el placer del texto, con sus dilogías y juegos de palabras» (140). Feliz es la irónica síntesis de Díez: «en los temas eróticos no siempre hay que acudir al contacto textual directo» (122). Comentario conectable con una de las incisivas preguntas que caracterizan su discurso crítico: «¿Hay erotismo sin 
cuerpo?» (75). Quizá la respuesta resulte orteguiana y por tanto negativa: el código cerrado o sutil sería un tipo histórico del arte deshumanizado que en cualquier época apela exclusivamente al intelecto y en este caso convierte en latentes abstracciones la genitalidad y la sexualidad. Es que en la poesía sutil de los siglos XIII-XVII procede el placer no de los sentidos excitados por el discurso monotemático y explícito, sino de una descodificación que, cuando triunfante, alcanza el clímax del entendimiento. Según he ido exponiendo desde 2010, proporcionan las «posibles pruebas» de tal proceder «las lecturas y comentarios de los contemporáneos o de los escoliastas», «las imitaciones del poeta o del texto», «las fuentes y usos de los tópicos en la tradición» y «la demostración del empleo de dilogías (apoyándose en textos inequívocamente eróticos o en valiosos diccionarios [...])» (64). Esta síntesis de Díez apunta al arduo trabajo que la historiografía, la crítica y la lexicografía diacrónica deben aún acometer.

El modelo que propone la distinción entre código abierto y cerrado despoja de su carácter historiográfico general a las moralizantes etiquetas erotismo y pornografía, y las resitúa en su exclusiva parcela: la historia transcurrida desde el siglo XIX. Quiero decir que no son conceptos operativos para analizar la diacronía completa desde el siglo XIII, sino componentes, a su vez analizables, del periodo decimonónico. Reintroducirlas en el modelo como categorías hiperónimas lo distorsiona: «los estudios sobre erotismo prefieren el erotismo de código o cerrado (o al menos el erotismo "honesto" [...]) que pueden cultivar los autores consagrados: es más literario, tiene más prestigio, escandaliza pero no tanto» (59). Sin embargo, me parece que el estado de la cuestión sobre la literatura sexual sigue privilegiando el código abierto, que por su escasa complejidad, o evidente sencillez, requiere un gasto menor de energía interpretativa. En 2001, por ejemplo, el espléndido catálogo de Cerezo se centró en los textos en abierto, «con algunos otros de codificación o cerrados, aunque su reconocimiento casi siempre descansa en su pertenencia a un contexto donde se insertan los textos abiertos» (58); y cuando Díez juzga «difícil» la «comparación» externa — ¿icon qué otro corpus reunido en la época sería posible?»- de los poemas del Cancionero de obras provocantes a risa, parece atender exclusivamente al código abierto, manejado por «los poemas eróticos de los Siglos de Oro», que «también se componen sobre la base de un lenguaje muy explícito» (50). Pero la comparación de la vertiente sutil de la colección de 1519 parece factible con otros cancioneros que también la frecuentaron. Ya lo evidenció Whinnom (1981) en su excelente libro pionero, en que por lo demás solicitaba a los críticos entrenarse en la poética dilógica para desprenderse de sus propios prejuicios estéticos.

En cuanto al erotismo honesto (59), quizá quepa enfocarlo desde una fértil pista establecida por Díez: la «raíz lejanamente común» entre literatura 
amorosa y literatura sexual (78). Entiendo que tal tipo de erotismo sería una variante menos de la segunda que de la primera, como probarían su asociación con el epitalamio o la lectura herreriana del soneto XXII de Garcilaso: «como no tropieza con dilogías» que «pudiera percibir como de mal gusto, como no hay descripción y como el texto descansa sobre una elaboración abstracta», Herrera «prefiere distraerse con suposiciones más o menos realistas», distinguiendo «tres tipos de belleza», al primero de los cuales se refiere con «el temido verbo gozar», que en «otros contextos» — los del código cerrado o sutil- presenta un "significado [...] claro», aunque «parece que Herrera (junto con Garcilaso) entiende el gozo de una manera mucho menos connotada» (61-63).

El código sexual abierto fue marginado en una diacronía sujeta a la presión estética -que estos poemas «pueden conectarse con lo vulgar, con lo zafio, con lo antiestético» redunda en su «ausencia de prestigio» (103)_, política, religiosa $\mathrm{y}$, finalmente, prejuiciosa por parte de los propios investigadores (134). Diríase que estos asumen el núcleo de la pregunta retórica de Ficino que oportunamente recuerda Díez: no se puede hablar con honestidad sobre lo deshonesto (81). De modo que, en la historia, «la expresión directa y abierta de los temas y motivos eróticos suele realizarse en ediciones clandestinas o copias manuscritas, pues es precisamente esa parte de la literatura erótica, por su inmediata percepción, la que despierta el mayor rechazo de poderes públicos o semiprivados, de moralistas y de ciertos autores» (58). Lo que supone que, en la historiografía, «el corpus aún dista de estar bien establecido, al menos tan establecido como otros» (135). La marginación histórica del código abierto ha sido prolongada, pues, por la historiográfica. Muchos de cuyos representantes - a la cabeza, el aún omnipresente Menéndez Pelayo- han «visto casi siempre en términos negativos» el «texto obsceno». Entre tantos casos, Díez aduce los de Rodríguez-Moñino y Buceta (22-23 y 25), el «silencio sobre el erotismo [...] del Libro del arcipreste» que denunció Sepúlveda, la infrainterpretación, "como dice Garrote Bernal», a la que se sometió a la Lozana andaluza (75-76) o los intentos — de Méndez Bejarano a Moñino- de desvincular a fray Melchor de la Serna de su poesía sexual (160-161). Tres razones explican este proceder: «Lo verdaderamente molesto para la tradición crítica ha sido el uso de la obscenidad, insoportable en algunos casos» (47) y que «el deslizamiento de lo inmoral a lo feo funciona como una magnífica coartada estética» (31). Díez expone la tercera con otra de sus inteligentes observaciones: «En la rigidez de los lectores e investigadores que rechazan la literatura erótica [...] seguramente hay, entre otros muchos prejuicios, un fuerte nexo entre erotismo y rareza» (215). Por no contar con una cuarta causa: el elitismo de tantos críticos que desprecian «los medios de transmisión poco 
prestigiosos (como la literatura de consumo)» y desconfían del «que para muchos podría ser un reprobable maridaje entre industria editorial (con el obvio fin de ganar dinero) y la recuperación del bagaje cultural del pasado (más que por su valor histórico o filológico, por su potencial ideológico)», prejuicio que afecta a la obra de Peratoner, uno «de esos extraños seres que viven de su trabajo» (236-237).

Tanto interés por arrinconar la literatura sexual de código abierto - la del cerrado es que muchas veces, por falta de práctica, ni se percibe como tal- produce una voluntaria distorsión, intolerable en otras disciplinas académicas, que sigue anclando a la nuestra en la servidumbre ideológica de todo pelaje y peaje. Que Díez insista en que el investigador ha de «evitar la sobreinterpretación, el arcaísmo y la desconexión que de los textos suele cultivar la teoría» y realizar luego el «esfuerzo» de «despojarse de los usos contemporáneos y acercarse a otro tipo de manifestaciones, más verbales o solo de este tipo», descartando además «la proyección de ideas y conceptos actuales sobre el pasado» (135), revela el mantenimiento de una perniciosa costumbre, en virtud de la cual el estudioso opta por su compromiso, conservador o progresista, en detrimento de su ingenieril deber filológico de trazar puentes con el pasado: «Las interpretaciones de la poesía erótica son complejas no sólo por la dificultad idiomática ni por los sobreentendidos cuyas claves el lector debe dominar, sino, quizá muy particularmente hoy en ciertas tendencias de la crítica, por la valoración ideológica» que presupone a su vez una «supuesta ideología subyacente» en los textos del pasado; probarla «precisaría dibujar tanto el público al que van dirigidos estos poemas como el contexto de su lectura, pues estudiar únicamente los contenidos del poema desde el prisma de una relectura actual puede deformar gravemente las conclusiones». Puede y lo hace. Así, en las que son conducidas desde el apriorismo de la «transgresión en la poesía erótica», que «a menudo parece», más bien, «un juego literario o un guiño entre amigos, por lo que no sorprende que la diversión buscada, ingeniosa y arriesgada, pase a veces por las burlas de los elementos más sagrados (el falo como símbolo de la resurrección)» (183-184). Por eso, la que en otro lugar he entendido como primera época de la literatura sexual (siglos XIII-XVII) parece regirse por el principio de que «la transgresión de un tabú añade diversión» (34), mientras que la segunda, a partir del XVIII, consigna a la transgresión como «arma arrojadiza contra la tradición católica y clerical de España» (25).

Otras fértiles vías de indagación propone Díez. «¿Se leían en voz alta los poemas eróticos? ¿Ante un público exclusivamente masculino? ¿Se acompañaban de gestos que subrayaran determinadas notas, posiblemente divertidas o burlescas?» (163). Quizá pueda empezar respondiendo el Libro del Arcipreste de Hita, 895-896: el «burro» «joglar» retoza, tañe el tambor y rebuzna 
«bien alto» hasta «atronar» al auditorio cortesano, «sañudo» con unas «caçurrías» que resaltarían sus voces y movimientos excitados, mientras que Ruiz siente la necesidad de disculparse ante unas oyentes de sus «cantares caçurros», las «dueñas» que ríen con ellos (estrofas 947-948). Díez apunta asimismo que «habría que delinear la relación de la poesía erótica con la literatura dominante para conocer qué es lo que se parodia y hasta dónde llega», $\mathrm{y}$ «contar con la variación de los códigos eróticos en relación con la tolerancia de la época» (163). Relación que los estudiosos han situado especialmente en dos lugares de silencio público: la imprenta y la censura. Un silencio roto en 1519 por la anomalía del Cancionero de obras de burlas, que «parece predicar una libertad expresiva que tardará muchos siglos en recuperarse en las prensas» (50).

Suele aceptarse que el arrinconamiento de la poesía sexual se corresponde con su marginación de la imprenta; sin embargo, la anomalía de 1519 fue más allá de la literatura sexual, dado el escaso aprecio coetáneo de la imprenta por la literatura en general, como probó Infantes (1984). Razón quizá no menor —pero habitualmente no aducida - de que, como tantas otras manifestaciones poéticas, las sexuales explícitas del Siglo de Oro quedaran confinadas «en los cancioneros manuscritos que no pueden alcanzar la imprenta» (50). Aunque no siempre, claro: frente a la teoría, la historia es el reino de las excepciones. Los seis epigramas de Alcázar coleccionados en Flores de poetas ilustres (FPI) funcionan como «separación de las distintas series de la antología» y presuponen «un contacto personal entre Espinosa y Alcázar». «Pero lo verdaderamente significativo» es que tres de ellos son «inequívocamente sexuales»: «poemas de esa densidad erótica» son «impresos» ¿porque «los hace aceptables su forma ingeniosa?». FPI 12 no prescinde de verbos como arremeter y coger, y emplea el «elemento erótico de primer orden» que son los pies; FPI 67 practica un erotismo «duro» con la secuencia picado, remedio y chupome, y el «extraordinariamente explícito» FPI 166 se centra en más signos de código cerrado, los de entrar en las dos puertas de Inés. Por su parte, como el tema de la nariz tratado por FPI 60 contenía implicaciones sexuales, fue acogido por Gracián en su Agudeza, xxxIII (151-155), creo que significativamente cerrando ese discurso dedicado a «los ingeniosos equívocos» que resultan esenciales en el código cerrado. En cuanto a FPI 18 y 182, no son «en principio» sexuales (152). De hecho, con la risa de FPI 18, situado delante de FPI 19, abrió Espinosa un díptico que le permitió montar una burla no sexual, sino antiherreriana (Garrote Bernal, 2009: 124).

Es evidente que la transgresión de un tabú deriva en censura y autocensura: «La censura, intensa en España y fuera de ella, es en sus formas civil y religiosa (y ambas excitan la autocensura) el instrumento de control ideológico por excelencia sobre todo a partir de la generalización de los textos impresos» 
(136). Aún en el siglo XIX, pocos «editores, autores y eruditos» estuvieron «dispuestos a desafiar las a menudo restrictivas leyes de imprenta» (215). Lejos de rasgarse las vestiduras por que hubiera censura, el magnífico historiador literario que es Díez la aprovecha para examinar las cuestiones que aborda: que la lengua fue «elemento netamente sexual» lo confirmaría Quijote, I, 13 («las partes que a la vista humana encubrió la honestidad son tales» «que sólo la discreta consideración puede encarecerlas y no compararlas»), pasaje que, aun no mencionando ninguna de esas partes, fue censurado por la Inquisición portuguesa en 1624 (192). Asimismo, Díez nota que la interesada censura que practicó el editor de Obras del insigne caballero don Diego de Mendoza brinda una excelente plataforma para examinar los límites de la honestidad. El primer grupo de testigos de época interrogados por Díez, los preliminares y las aprobaciones de 1610, subraya la «castidad» y la carencia de lo malsonante y lo escandaloso en el libro, mientras que Hidalgo une en su prólogo «burlas», «ingenio», «agudeza», «donaire» y falta de «dignos respetos» como rasgos de la poesía «bien conocida» de Hurtado que no publica; al tiempo, sus «argumentos» «de alcance muy diverso», la excluyen de la imprenta porque habría sido compuesta dentro de un círculo de amistades «poco saludable en el fondo» y, tirando del «juego de bibliofilia (que prestigia los manuscritos)», sostuvo, con su aquel de cinismo, que la marginación «evitará a estos textos la vulgaridad del común», de modo que tales composiciones «serán más estimadas de quien las tenga» (91-95). Otro testigo es el anotador del manuscrito BP 2805, «ligeramente anterior» a 1610, que colecciona poemas sexuales no publicados en la edición y contiene «marcas y comentarios posiblemente de uno de sus poseedores», sañudo con A la zanahoria y «Dicen que dijo un sabio muy prudente...», aunque no anote otros poemas sexuales, pues «se preocupa más por la ortodoxia religiosa y se muestra mucho más permisivo en materia erótica» (101-102). Conclusión que Díez deriva de su detenido estudio del anotador de ese manuscrito, descontento, como otros, con culo y rabo, si bien quizá manejara un «concepto de lo reprobable» que «no coincide con el de épocas posteriores» (Díez Fernández, 2008: 108 y 98).

Con todo, la censura de los guardianes oficiales del orden - auténtico engranaje de tabúes- «no tiene jurisdicción de hecho en los textos manuscritos» (127), ni puede operar sobre otros «canales de difusión», como la memoria, auxiliada por una «brevedad» que, siendo «importante en su conexión con el ingenio» en el epigrama y tantos otros textos, logra «más fácilmente la memorización y la ulterior copia manuscrita o a la inversa» (134 y 137). Y si en el siglo XIX «los canales de transmisión de la literatura erótica desembocan muy a menudo en un coleccionismo oculto» (223), en épocas pasadas - y de extensión secular mayor que la moderna y contemporánea-, «la oralidad se come una gran parte de la tarta literaria» en canciones, recitados o academias, 
a lo que deben sumarse «manifestaciones escritas de carácter privado» como cartas, cartapacios o libros de memoria, por lo que quedó «un enorme campo fuera de ese control» censor (136). Por lo demás, «la seguridad de impresores y editores clandestinos» del XIX «obliga a las tiradas cortas» e «impone» la «ausencia de datos bibliográficos, o su falseamiento»; pero hay también excepciones: «es muy posible» que Erato retozona. Poesía erótica de D. F. A. (1839) «no trate de ocultarse en datos falsos» (223-224).

Las vicisitudes de una transmisión así tienen consecuencias esperables: «No sorprenderá que los textos eróticos, y sobre todo si son extensos, se documenten menos en las fuentes que los poemas serios» (124). Por el lado opuesto, la poesía sexual «parece proclive a las amplificaciones» (127), una tarea de «copista» «que siente, como otros, la llamada a probar su ingenio y su técnica literaria en un poema erótico y burlesco» (130), lo que hace «raro que dos fuentes compartan una amplificación», a veces una segunda versión del autor y otras una continuación: la «versión ampliada» de $A$ las damas de palacio de Hurtado que es El fraile (o fray Melchor de la Serna) es caso que «puede ser muy significativo sobre la confección de textos amplificados» (127-128). Asimismo, se multiplican los problemas de atribución, sobre todo cuando los autores, como Melchor de la Serna o Damián Cornejo, son clérigos afectados por «los intereses de los difamadores o maledicentes junto a los de los firmes, y no por ello menos dudosos, defensores de la rígida moral», dada la «caritativa tendencia de arrojar dudas sobre la verdadera paternidad de unos textos atribuidos a frailes» (159-160). Creo que, con los requisitos de saber leer y escribir en romance y en latín, y de pertenecer a la clase que detenta la hegemonía cultural -y por tanto tiene licencia, sea cual sea el periodo examinado, de saltarse sus prescripciones - hay una alta probabilidad de que tales dudas terminen resolviéndose en respuestas afirmativas. El caso es que por fin se ha llegado a un estado de conocimientos que permite que «no resulte ya chocante la dedicación de clérigos y frailes al cultivo de la literatura erótica» (162). Entiendo que lo chocante del caso se acabará contemplando como un anacronismo más de la historiografía; pero eso ocurrirá cuando esta abandone al fin sus sesgos y recurra sistemáticamente a una parcela de la bibliografía apenas consultada: la dedicada a la historia de la Iglesia. Y no solo a los índices de libros prohibidos.

La imprenta solicitó masivamente a la literatura sexual cuando aquella impuso su radio multiplicador de alcance en su fase industrial (o sea, democrática). Entonces, uno de los más lucrativos negocios de siempre, el del sexo, fue compatible con una libertad de expresión ligada en Occidente a una generación de plusvalías extraordinariamente eficaz como persuasión. Tal capacidad de convencimiento venció al puritanismo protestante algo más de un siglo antes que al católico. Al publicar de nuevo en el Londres de $1841 \mathrm{el}$ 
Cancionero de obras de burlas provocantes a risa, el extraordinario Luis de Usoz y Río, «un español alejado ideológicamente de gran parte de sus compatriotas» (99), usó la literatura sexual como recurso político — según habían hecho católicos y protestantes en las guerras civiles francesas (Alexandrian, 1989: 105-107) — , de modo que «la edición de cancioneros eróticos nace con una voluntad ideológica»: transformarlos «en arma arrojadiza contra el catolicismo y la visión más tradicionalista de la historia cultural de España» (224). Por eso, desde mediados del XIX «no es casual que sean los extranjeros y los españoles en el exilio quienes recuperen un tipo de poesía que se llama burlesca» (99). Sucedió también con la sexual de Hurtado de Mendoza, que alcanzó la imprenta en 1875 con Morel-Fatio, editor del ms. BNP 258, y en 1914 con Foulché-Delbosc. Pero esa parcela, rescatada en Poesías satíricas y burlescas (1876) de Hurtado por un anónimo (quizá Knapp), volvió al «gueto» en sus Obras poéticas (1877), excepción hecha de El bombodombón y «alguna sátira», que Knapp, aunque extranjero, situó al final: «no se trata ya de una explícita condena moral (pues ni siquiera Hidalgo [en 1610] la formula como tal), sino del recurso a la condición inédita de los poemas» que «no son fáciles de integrar» aún «o solo encuentran un acomodo incómodo» (99-100). La «dignificación total» se demoró hasta «i1941-1943!», cuando González Palencia y Mele comentaron todos los textos de Hurtado, incluidos los sexuales (103).

Como he pretendido mostrar, en «Fiebre de luz y río de corceles». Poesía y erotismo áureo elabora J. Ignacio Díez una cuidada crítica literaria de la que se extrae un completo conocimiento de los textos abordados, no menos que directrices para una historia de la poesía sexual española. Directrices guiadas por una teoría que es hija no de la especulación, mucho menos del prejuicio, sino de la atenta lectura de textos recurrentes. Este libro, pues, consolida a su autor como uno de los principales expertos — creo sinceramente que ya el primero- en la poesía sexual del Siglo de Oro.

\section{BIBLIOGRAFÍA}

AlEXANDRIAN, S. (1989): Historia de la literatura erótica, Planeta, Barcelona. Botrel, J. F. (2018): «Fabricación del libro en Madrid», Cuadernos de Ilustración y Romanticismo, 24, pp. 226-242.

DíEz Fernández, J. I. (2003): La poesía erótica de los Siglos de Oro, Laberinto, Madrid.

(2008): «Lecturas de una lectura: el manuscrito hablador», en Á. Alonso y J. I. Díez (eds.), «Non omnis moriar». Estudios en memoria de Jesús Sepúlveda, Universidad de Málaga, pp. 93-114. 
(2019): «Fiebre de luz y río de corceles». Poesía y erotismo áureo, José J. Olañeta, Palma de Mallorca.

GARROTE BERNAL, G. (2009): «Ensayo de memoria herrerianista hacia la poesía sevillana del siglo XVII», en Congreso Internacional Andalucía Barroca, III. Literatura, Música y Fiesta. Actas, Bilbao, Junta de Andalucía, pp. 117-128.

(2020): Con dos poéticas. Teoría historicista de la literatura sexual española, Agilice Digital, Valladolid.

Herrera, F. de (2001): Anotaciones a la poesía de Garcilaso, Cátedra, Madrid. Ed. I. Pepe y J. M. Reyes.

INFANTES, V. (1984): «1524», Journal of Hispanic Philology, 8.2, pp. 139-145.

Miaja DE LA PEÑA, M. T. (2012): “"De todos los instrumentos, yo, libro, só pariente". La relación entre los instrumentos y el "rimar e trovar" en el Libro de buen amor», en A. Martínez y A. L. Baquero (eds.), Estudios de literatura medieval, Universidad de Murcia, pp. 599-605.

SEPÚlvedA, J. (2001): «Con un soneto de Quevedo: léxico erótico y niveles de interpretación», La Perinola, 5, pp. 285-319.

SolÉ, J. (1976), El amor en Occidente durante la Edad Moderna, trad. X. Gispert, Argos, Barcelona, 1977.

WhinNom, K. (1981): La poesía amatoria en época de los Reyes Católicos, University of Durham. 